University of Wollongong

Research Online

Faculty of Business - Papers (Archive)

Faculty of Business and Law

2014

National electronic health records and the digital disruption of moral orders

Karin Garrety

University of Wollongong, karin@uow.edu.au

Ian McLoughlin

Monash University

Rob Wilson

Newcastle University

Gregor Zelle

University of Wollongong, gz742@uow.edu.au

Mike Martin

Newcastle University

Follow this and additional works at: https://ro.uow.edu.au/buspapers

Part of the Business Commons

Research Online is the open access institutional repository for the University of Wollongong. For further information contact the UOW Library: research-pubs@uow.edu.au 


\title{
National electronic health records and the digital disruption of moral orders
}

\author{
Abstract \\ The digitalisation of patient health data to provide national electronic health record systems (NEHRS) is a \\ major objective of many governments. Proponents claim that NEHRS will streamline care, reduce \\ mistakes and cut costs. However, building these systems has proved highly problematic. Using recent \\ developments in Australia as an example, we argue that a hitherto unexamined source of difficulty \\ concerns the way NEHRS disrupt the moral orders governing the production, ownership, use of and \\ responsibility for health records. Policies that pursue digitalisation as a self-evident 'solution' to problems \\ in healthcare without due regard to these disruptions risk alienating key stakeholders. We propose a more \\ emergent approach to the development and implementation of NEHRS that supports moral re-ordering \\ around rights and responsibilities appropriate to the intentions of those involved in healthcare \\ relationships.
}

\section{Keywords}

Australia, National electronic health record systems, Moral order, Digital disruption, Personal control, Policy, Rights, Responsibilities

Disciplines

Business

\section{Publication Details}

Garrety, K., McLoughlin, I., Wilson, R. G., Zelle, G. \& Martin, M. (2014). National electronic health records and the digital disruption of moral orders. Social Science and Medicine, 101 70-77. 


\title{
National electronic health records and the digital disruption of moral orders
}

\author{
Karin Garrety, Ian McLoughlin, Rob Wilson, Gregor Zelle, Mike Martin
}

\begin{abstract}
The digitalisation of patient health data to provide national electronic health record systems (NEHRS) is a major objective of many governments. Proponents claim that NEHRS will streamline care, reduce mistakes and cut costs. However, building these systems has proved highly problematic. Using recent developments in Australia as an example, we argue that a hitherto unexamined source of difficulty concerns the way NEHRS disrupt the moral orders governing the production, ownership, use of and responsibility for health records. Policies that pursue digitalisation as a self-evident 'solution' to problems in healthcare without due regard to these disruptions risk alienating key stakeholders. We propose a more emergent approach to the development and implementation of NEHRS that supports moral re-ordering around rights and responsibilities appropriate to the intentions of those involved in healthcare relationships.
\end{abstract}

Keywords: Australia; National electronic health record systems; Moral order; Digital disruption; Personal control; Policy; Rights; Responsibilities

\section{Introduction}

Many governments are investing in nation-wide information systems that will collate individual health records and make them available across organisational and geographic boundaries (Brennan, 2007; Morrison, Robertson, Cresswell, Crowe, \& Sheikh, 2011; Stroetmann et al., 2011). These systems, which for the purposes of this paper we call NEHRS (National Electronic Health Record System/s) are often integral components of broader attempts to reform healthcare. Policymakers, politicians and some researchers claim that digitising health information will help eliminate inefficient paper-based systems and cut costs, while facilitating the development of new, better coordinated models of 'paperless' care (Christensen, Grossman, \& Hwang, 2009; Hunt, 2013). Making electronic records available to citizens, proponents claim, will also encourage them to take more responsibility for their own health (Ball, Smith, \& Bakalar, 2007; National Health and Hospitals Reform Commission, 2009a).

However, existing research suggests that although these visions are compelling, translating them into workable systems is highly problematic (Deutsch, Duftschmid, \& Dorda, 2010; Greenhalgh, Russell, Ashcroft, \& Parsons, 2011). As well as the technical challenges of replacing or connecting diverse legacy systems, new forms of governance are needed to manage the potential risks associated with the wider distribution of potentially sensitive information. In many nations, including England, Australia and the Netherlands, attempts to formulate new rules at a national level around patient consent, privacy, data quality and access in relation to NEHRS became mired in controversy. In England a 'big opt out' campaign forced changes to policy and contributed to significant delays in the roll out of a national 'summary care record' (Carvel, 2006; Cross, 2008). The Dutch Senate abandoned plans for a NEHRS in 2012 amid concerns about privacy (Smits, 2013). Australia's NEHRS has also encountered opposition from privacy groups and doctors who are concerned about its security, safety and utility (Coiera, Kidd, \& Haikerwal, 2012; Dearne, 2012a).

In this article we argue that one reason NEHRS have been so difficult to implement is that policymakers have seriously underestimated the degree to which digitalisation disrupts existing social, moral and medico-legal orders through which healthcare is governed and delivered. Too often, these disturbances are pushed into the background while the technical capabilities of NEHRS 
are foregrounded as 'the solution' to the challenges facing healthcare systems. Centralised authorities attempt to resolve the resulting disruptions by trying to impose new rules that seemingly fail to satisfy interested parties. We suggest that a more holistic, flexible and emergent approach that prioritises and supports the intentions of those involved in care relationships may help address some of the difficulties encountered by nations attempting to introduce NEHRS. Governments need to demonstrate more commitment to providing adequate opportunities for those engaged in healthcare to explore anticipated and unexpected shifts in their identities, practices and relationships, and to consider modes of governance that support the intentions of those involved in care as it evolves in the digital age.

Our argument is structured as follows. In the next section we develop the idea of healthcare as a cluster of intersecting and negotiated moral orders that, while stable enough to facilitate care most of the time, are also subject to change and disruption. These orders emerge out of and shape interactions across many sites, from private, situated healthcare encounters to public debates about national health policy. Our focus in this article is on the latter, as it is in the policy arena that governments have tried, without much success so far, to manage the disruptions generated by the introduction of NEHRS. We place these debates within a broader context of shifting power relationships among doctors, patients and the state, and outline the pivotal role that medical records play in mediating these relationships. Debates surrounding the introduction of a NEHRS in Australia are then presented to illustrate how the innovation disrupted established patterns of formalised rights and responsibilities. While these disruptions open up possibilities for more connected, person-centred care, they also create ambiguities that may hinder implementation if, as occurred in Australia, parties who perceive the innovation as threatening attempt to fortify their positions within pre-existing orders. We conclude by considering approaches that may facilitate a more productive way of reaping the potential benefits of NEHRS while working through the governance challenges they pose.

\section{The multiple negotiated orders of healthcare}

The idea that healthcare is delivered through a series of negotiated orders grew out of ethnographic observations of work in hospitals in the 1960s. Strauss, Schatzman, Ehrlich, Bucher, and Sabshin (1963), Strauss, Fagerhaugh, Suczek, and Wiener (1985) observed how the work of caring for patients was not determined by rules or procedures, but achieved through ongoing actions and interactions carried out in response to contingencies as well as formal and informal rules and expectations. Negotiated orders are not just evident within single organisations, however. They also emerge out of and shape relationships among organisations and entities in their environment, such as client groups and government agencies (Strauss, 1982). Following this line of analysis, we can view healthcare as occurring within arenas populated by different social worlds - lay people, medical professionals, policymakers and bureaucrats - who collectively negotiate the formal and informal 'rules' that shape the delivery of care (Clarke, 2005).

An important aspect of these negotiations concerns the moral orders of healthcare, that is, systems of 'rights, obligations and duties' that mediate relationships among actors in the arena (Langenhove \& Harré, 1994). Moral orders are multi-layered and often contested. They can be found at different levels of generality - from the policies and regulations that allocate rights and responsibilities to institutions, to the implicit 'rules' that shape interactions in single healthcare encounters (Harré, Moghaddam, Cairnie, Rothbart, \& Sabat, 2009; Thévenot, 2001). Moral orders are also integral to the discursive production of identities, as individuals and institutions position themselves and others in relation to these orders. Positions, in this view, are 'clusters' of rights and responsibilities that 'belong' to individuals as members of collectives, or that individuals claim and contest as they create themselves and their institutions as competent, moral entities. Positions are adopted, negotiated 
and challenged with regard to people's capacities, training, vulnerabilities and social and institutional locations (Harré et al., 2009; Langenhove \& Harré, 1994). Thus, in most developed nations, people position themselves as having 'rights' to healthcare based on their vulnerability to sickness or disability, and see its provision as a state 'responsibility'. There are many, often contestable, moral orders within this broad pattern, especially around controversial issues such as vaccination, contraception, end-of-life care and abortion (Blume, 2006; Simonds \& Ellertson, 2004).

Since the middle of last century, doctors have wielded considerable power in healthcare arenas. Based on their training and expertise, they have claimed and exercised rights to control the content and conditions of their work. As Hughes noted, these rights are linked to doctors' assumption of major responsibilities for healthcare outcomes. In common with other occupations in which mistakes can be fatal, they 'build up collective defenses against the lay world' (Hughes, 1971: 318). They claim rights to police the boundaries of their profession - who is allowed in, processes for managing accidents and mistakes, the circumstances in which colleagues are called to account, and the criteria according to which they are judged competent or otherwise (Hughes, 1971; Willis, 1983). As we discuss below, medical records are crucial for policing and legitimating medical work.

In recent decades, rising costs and expectations of improvements in the quality of care and health outcomes, have prompted policymakers to negotiate new orders that erode some of these rights. Providers are now often obliged to follow standardised evidence-based protocols with payments linked to compliance (Bury \& Taylor, 2008; Christensen et al., 2009). Policymakers are also attempting to reduce costs by 'empowering' people to take more responsibility for their own health. Proponents of NEHRS claim that the technology has the potential to facilitate this empowerment by providing citizens with access to their own records and electronic connections to multiple carers when illnesses are chronic and complex (Christensen et al., 2009). However, merely implementing NEHRS without paying attention to and managing disruptions to entrenched distributions of rights and responsibilities can lead to frustration and waste (Westbrook \& Braithwaite, 2010). The benefits of NEHRS, we suggest, are unlikely to be realised until we understand their implications, not only for models of care, but also for the moral orders that govern medical practice and the interactions we all have with our healthcare systems.

\section{Records in the moral orders of healthcare}

The medical (or health) record is a 'mundane yet surprisingly multi-layered technology' (Berg \& Harterink, 2004: 15) that has evolved as healthcare practices have changed. Initially records were 'owned' by practitioners, as they chronicled symptoms and illness trajectories for teaching and research (Reiser, 1991a). These often idiosyncratic accounts helped develop the expert knowledge that legitimates doctors' rights to practice. From the 19th century onwards such narratives were supplemented by more organised records designed to facilitate additional modes of ordering linked to new positions within the healthcare arena. With the introduction of managers in hospitals, separate records were used for billing and administration (Siegler, 2010).

As the influence of scientific management spread, initially in the United States then elsewhere, attempts were made to enhance the efficiency and effectiveness of hospitals through more reliable, standardised record keeping (Reiser, 1991b; Berg \& Harterink, 2004). Reformers in the early 20th century proposed using records to 'fix responsibility' for adverse outcomes (Reiser 1991b: 908). A new position of 'medical record librarian' emerged with rights to rationalise medical note-keeping into prescribed formats. These changes were initially resisted by doctors who viewed them as encroachments on their rights to practice as they saw fit. However, more extensive and standardised record -keeping was also in their professional interests as it facilitated research and helped police standards of competent practice that enhanced public trust and prestige. By the 1930s hospital 
records in the US were considered reliable enough to be admitted as evidence in court cases. This intersection of legal and healthcare arenas created new medico-legal responsibilities, rights and risks, and further incentives for comprehensiveness and standardisation (Berg \& Harterink, 2004; Berg \& Winthereik, 2004). Similar trends have been evident in primary care where records have also become increasingly standardised (Purves, 2002).

The moral orders of medical record keeping have also been shaped by the changing position of patients, now recast as active participants or 'consumers' of healthcare (Harris, Wathen, \& Wyatt, 2010). Until the 1960s it was common, at least in the US, for doctors to withhold diagnoses from patients thereby robbing them of the capacity to contribute to decisions about their care (Laine \& Davidoff, 1996). This situation has changed, and most patients now expect to be informed about diagnoses and options for treatments available to them. While some, especially those with serious and/or chronic conditions, still prefer doctors to make decisions about care (Sinding et al., 2010) there is a broad consensus that patients should have access to their records (Ross \& Lin, 2003).

Given the multiple purposes of medical records and the diversity of actual and potential audiences, it is not surprising that tensions surrounding their production and use endure. Siegler (2010) noted that complaints about the 'variable quality' of records go back 'almost a century', along with attempts to improve them. Since the 1960s, reformers have looked to computers to 'modernise' record keeping, but it is increasingly clear that merely digitising data does not address the challenges involved in accommodating diverse work routines and expectations. Nor does it necessarily satisfy the different audiences that may be interested in the information, especially when systems span organisational boundaries (Greenhalgh et al., 2011; Hackl, Hoerbst, \& Ammenwerth, 2011; Jenkings \& Wilson, 2007).

Some of the enduring tensions surrounding medical records can be traced to competing moral priorities in contemporary societies (Boltanski \& Thévenot, 2006). Boltanski and Thevenot identified six 'orders of worth' that shape the way people develop and justify claims about how things should be. The drive towards standardised, complete and accessible records prioritises efficiency, which sometimes clashes with more traditional medical values of trust and individualised care. Decades ago, Garfinkel et al. documented tensions between different moral priorities in medical record keeping. While administrators in their research setting valued efficiency and 'actuarial' record keeping that privileged 'completeness, clarity, credibility and the like' (Garfinkel \& Bittner, 1967: $190)$, healthcare providers at the frontline of delivery were more interested in recording just enough detail to indicate that they had satisfied their contractual or moral obligations to patients in their care (Garfinkel \& Bittner, 1967).

Many advocates of NEHRS value the technology's potential to provide doctors with 'all of the information about all of their patients all of the time' (Rauber, 2008). This actuarial view homogenises data into a single desirable commodity - the more the better - with the integration of this information as 'the solution' to problems in healthcare. By focussing on data availability rather than the moral and contractual aspects of care, these advocates underestimate the extent to which the rights and responsibilities attending the collection and exchange of health information are intimately bound up with the intentions of those delivering care in particular contexts (McLoughlin \& Wilson, 2013). As NEHRS are designed and implemented, these issues come to the fore in contests over governance. Below, we illustrate how these contests emerged during the implementation of a NEHRS in Australia.

\section{The troubled history of Australia's NEHRS}

\section{Method and sources of data}


This article is based on a retrospective study of the development of NEHRS in Australia. We collected relevant documents and organised them for analysis using 'Zotero' software. A chronology of significant events was constructed, and key stakeholder bodies and opinion leaders identified. We selected 106 documents in which they presented and argued their positions and/or responded to the positions constructed for them by others. Significant players in Australia's NEHRS policy arena were clustered as follows: the Federal Government and its advisory bodies (National Health and Hospital Reform Commission, Department of Health and Ageing, Health Ministers, National e-Health Transition Authority, Senate Committee for Community Affairs), consumer groups (Consumers' Health Forum, Consumers e-Health Alliance), health informatics groups (Australasian College of Health Informatics, the Medical Software Industry Association), privacy advocates (Office of the Australian Information Commissioner, Australian Privacy Foundation) and peak professional bodies representing doctors (Australian Medical Association, Royal Australian College of General Practitioners). Statements relating to risks, problems, capacities, vulnerabilities, rights and responsibilities surrounding key elements of the moral orders governing health records, for example, consent and access rules, responsibility for data quality, liability for negligence, mistakes and accidents were identified and collated in a table (142 pages) that summarised the positions of participants in the arena, and their responses to positions constructed for them by others. The table was read through multiple times to identify key points of tension. Developing interpretations were circulated and discussed among the research team to produce the account below.

\section{Moral ordering in Australia's healthcare policy arena}

Australia has a complex healthcare system, with responsibilities for policies, funding and delivery shared among state, territory and federal governments (Willis, Reynolds, \& Keleher, 2008). While distributions of rights and responsibilities around information systems in single organisations or across regions can be locally negotiated, designing and implementing NEHRS requires national legislation, resourcing and coordination (Coiera, 2009).

Health ministers have considerable rights and responsibilities for setting policy agendas. However, they typically act selectively on recommendations put forward by taskforces and commissions convened to research and suggest 'solutions' to perceived problems. Draft policies are usually released for discussion and submissions invited from interested parties before legislation to implement plans is introduced into parliament. Healthcare policies often seek to redistribute rights, responsibilities and resources among providers, citizens and governments. The drafting and submission stage provides opportunities for participants in the healthcare arena to respond to the positions created for them by policymakers and others exercising influence in the arena. This activity occurs in what Thévenot (2001) calls a 'public regime of justification' - a mode of engagement in which actors debate and set general conditions such as rules and standards that shape interactions across multiple microsocial situations. This engagement is a 'high level' mode of moral ordering, and participants are expected to legitimate their claims with reference to the common good. However, this 'global' ordering can disrupt local routines and relationships. For workable sociotechnical infrastructures to emerge from this activity, plans and systems need to be flexible enough for tensions between local and high level orders to be addressed (Star \& Ruhleder, 1996).

The following account reveals the tensions that emerged in the public regime of justification in the lead up to the implementation of a NEHRS in Australia in 2012. Despite the tension, policymakers and others persisted with a belief in the capacity of digital technology to provide the core of a 'solution' to problems plaguing healthcare. As has been the experience in other jurisdictions (Brennan, 2007; Hackl et al., 2011) this has resulted in a system that many claim is far from optimal (Foo, 2013a; Townsend,2012). 
Policymakers' proposals: a 'person-controlled' EHR

Health ministers in Australia have been interested in NEHRS since the early 1990s (Clarke, 1992). However, efforts to build such systems have had to contend with the legacy of the 'Australia Card' controversy of the 1980s, when citizens concerned about privacy blocked plans to introduce a compulsory national identity card (Clarke, 1988). An attempt to build a NEHRS during the 2000s collapsed, as the complexities of the proposal came to be realised (Dearne, 2005, 2009; Deloitte, 2008; Fujitsu Consulting, 2004). In 2005 the government established a National e-Health Transition Authority (nehta.gov.au) to work on technical components, but concerted attempts to design and implement a new system did not achieve momentum until 2009, when a commission convened to help reform healthcare in Australia recommended the introduction of a 'person-controlled' electronic health record - hereafter called the PCEHR (National Health and Hospitals Reform Commission, 2009a,b).

According to the reform commission, the PCEHR would have multiple benefits:

The introduction of a person-controlled electronic health record for each Australian is one of the most important systemic opportunities to improve the quality and safety of health care, reduce waste and inefficiency, and improve continuity and health outcomes for patients. Giving people better access to their own health information through a person-controlled electronic health record is also essential to promoting consumer participation, and supporting self-management and informed decision-making (National Health and Hospitals Reform Commission, 2009a: 8).

The federal health minister endorsed these proposals and set a starting date for the PCEHR of 1 July 2012.

Throughout the development of the PCEHR spokespeople from the government and its advisory bodies have highlighted 'person-control' as a significant feature of the design of NEHRS in Australia. The reform commission made an emphatic distinction between earlier plans for NEHRS that were 'controlled by the health provider (or held centrally) and shared with other approved providers but with limited or no access by the patient' and the proposed PCEHR which, by contrast, would be 'controlled by the patient and shared with nominated health care providers' (National Health and Hospitals Reform Commission, 2009b: 11-12). This represents a significant shift in the moral orders that have customarily governed the use of information in the healthcare sector. While patients' rights have been expanding for decades, the suggestion that they control their EHR has far reaching implications for the rights and responsibilities of healthcare providers, patients and state.

The PCEHR creates new positions for citizens with attendant discursively constructed (and contested) rights and responsibilities. The reform commission positioned 'persons' as 'gatekeepers of their own health record' (National Health and Hospitals Reform Commission, 2009b: 8). Design principles devised by government agencies outlined the following rights for citizens: deciding whether to have a PCEHR and if so what information is included; access to the record and a capacity to set controls determining which healthcare providers and other people (carers, family members) can see it; and access to audit trails to see who has accessed their PCEHR and what they have done with it (Department of Health and Ageing, 2011). The government portal enabling registration informs citizens that:

You will control what goes into your eHealth record, and who is allowed to access it. Over time an eHealth record will help put you at the centre of your own healthcare (Department of Health and Ageing, 2012) 
With these rights come new responsibilities:

It will be imperative that consumers are made aware that with the right to control access to their health record comes a responsibility that incomplete information on their P[C]EHR may harm their health care. Consumers need to develop an understanding that incomplete records could pose a danger to their contacts, their carers, and the public if not made available to their clinical care team (National Health and Hospitals Reform Commission, 2009b: 13-14)

The moral orders of healthcare are relational. That is, shifts in the position of patients engender changes in the positions of implicated others, most notably the doctors who hold major responsibilities for ensuring that competent care is delivered.

\section{The re-positioning of doctors and doctors' responses}

Before technologies such as the PCEHR became possible, doctors were in control of, and responsible for, the medical records of patients in their care. The 'use and disclosure' of that information 'within the reasonable expectations of the patient at the time of collection' did not need their explicit consent, and patients' access to their records was at the provider's discretion. Doctors were advised that if records were made available 'it is normally desirable for the medical practitioner to be present to clarify any aspects and to permit any concerns of the patient to be discussed and resolved' (Royal Australian College of General Practitioners, 2002).

The PCEHR disrupts these established arrangements by creating an information repository that still requires doctors to be involved, but with ambiguous responsibilities and uncertain control.

Advocates of the technology position providers as 'beneficiaries' of the PCEHR on the grounds that it will enable them to 'access health information more efficiently' and 'deliver more effective healthcare' (Department of Health and Ageing, 2011: 15). The peak professional bodies for doctors the Australian Medical Association (AMA) and the Royal Australian College of General Practitioners (RACGP) - have made statements supporting e-health (e.g. Australian Medical Association, 2011; Royal Australian College of General Practitioners, 2011a) but they have also contested the positions created for them by the PCEHR, on the grounds that it imposes additional unclear responsibilities on them with, they claim, marginal benefits and unknown medico-legal risks. Participation by providers is voluntary, but the government has the right to withhold payment of certain 'incentives' unless they take part (Ramli, 2012).

Although the PCEHR is ostensibly owned and controlled by lay people, its creation requires a 'nominated provider': 'an identified healthcare provider involved in the ongoing care of the individual who has agreed with the individual to create and manage their Shared Health Summary' (Department of Health and Ageing, 2011: 50). The shared health summary initially includes allergies and adverse reactions, medicines, medical history and immunisations. The PCEHR will also contain 'event summaries' and clinical documents, such as discharge summaries, specialist letters and pathology results, submitted by any 'participating provider' with the consent of the patient. People cannot restrict access to their shared health summary but they can limit what is included and who sees the additional documents. They can also remove documents if they choose to do so (Department of Health and Ageing, 2011).

Doctors claim that explaining the PCEHR to patients, negotiating what is included, outlining the risks of 'hiding' data and maintaining records imposes additional work, risks and responsibilities for which they should be compensated (Dearne, 2012b). After resisting, the government agreed to remunerate doctors for longer consultations involving the PCEHR (Royal Australian College of General 
Practitioners, 2012). There was also concern about 'the expectation that medical practitioners will trawl through swathes of information each time they access a PCEHR' (Australian Medical Association, 2011: 4). Doctors' obligations to view information in the PCEHR are unclear. The AMA has tried to limit implied responsibility in this area. Its guidelines for doctors state, 'There is no obligation for you to review any or all of the information in a patient's PCEHR' (Australian Medical Association, 2012: 16).

The AMA and RACGP are also concerned about what they see as risks associated with 'personcontrol'. They lobbied successfully to remove a capacity for people to set 'no access' controls that would hold even in emergencies (O'Brien, 2011). More pervasive than this concern however, are what they fear are uncertain medico-legal risks associated with the availability of records whose degree of (in)completeness and up-to-dateness is unknown to doctors and out of their control. The reform commission that initially proposed the PCEHR anticipated these concerns, noting that it is 'only one piece of the puzzle', not 'a reliable record in itself' (National Health and Hospitals Reform Commission, 2009b: 13). The National e-Health Transition Authority also presented the risks as no different to the current situation, in which 'consumers ... exercise choice in the information they provide to different healthcare providers' (National e-Health Transition Authority, 2012: 4). The PCEHR is not meant to be a replacement for doctors' records. Providers need to keep their own records in parallel, and communicate with others using their customary methods (Australian Medical Association, 2012).

The PCEHR is some way, it seems, from providing a 'data rich environment ...that connects all participants with relevant, accurate and secure information in real-time' that reformers promised (National Health and Hospitals Reform Commission, 2009a: 127). Instead, the Australian Medical Association $(2011: 3,9)$ claims the environment will be 'clinically equivalent' to the present, with a 'negligible' capacity to reduce mistakes and prevent duplication. Moreover, government assurances that the risks and responsibilities are no different to pre-PCEHR days have not, it appears, placated the medical profession. Responsibilities for keeping the PCEHR as up-to-date and complete as possible are unclear. According to the PCEHR design principles, nominated providers are 'required to assert that they have assessed and described all aspects of the Shared Health Summary and taken reasonable steps to verify the accuracy of information' (Department of Health and Ageing, 2011: 51). No further statements regarding provider responsibilities for data quality are included in the design principles, beyond an assurance that, 'nominated providers are not expected to update a Shared Health Summary outside of a consultation with an individual' (Department of Health and Ageing, 2011: 51). Doctors' bodies give ambiguous advice. The RACGP states that, 'the onus will be on the general practitioner to ensure the accuracy and completeness of the PCEHR content' (Royal Australian College of General Practitioners, 2011a: 3). The Australian Medical Association's (2012: 17) guidelines on the other hand assert, 'There is no additional responsibility for Nominated Healthcare Providers to curate, monitor or review any other information on their patients' PCEHRs, outside of creating or reviewing a Shared Health Summary for the patient'.

Doctors position themselves as 'burdened' rather than assisted by the system (Royal Australian College of General Practitioners 2011b; Australian Medical Association, 2011). The AMA guidelines advise doctors to be defensive, recording details of discussions they have with patients regarding the PCEHR, and all interactions they have with it. In other words, they are advised to recontextualise the information obtained from the record, incorporating it into their own separate records of their contractual obligations to patients, should they ever be subjected to scrutiny. As the Australian Medical Association (2012: 22) warns, 'the medico-legal risks [of the PCEHR] for medical practitioners and medical practices are unknown until case law develops'. The AMA is responding to what it sees as uncertainties in the distribution of rights and responsibilities around the PCEHR by advocating a defensive elaboration of current record keeping practices. 
Having said this, doctors' bodies are not entirely opposed to a NEHRS. The RACGP is supportive provided the 'potential risks' are clarified and resolved (Royal Australian College of General Practitioners, 2011a). The Australian Medical Association (2011: 2) sees much promise in a, 'simple, trustworthy and secure electronic health record that integrates easily with current workflow practices'. The current PCEHR in its view has 'unacceptable complexities' due to the 'disproportionate emphasis given to the concerns of an extreme minority who wish to mask details of their health record' (Australian Medical Association, 2011: 2). According to AMA President Hambleton, 'the consumer groups have maintained control over the records to the detriment of all consumers' (quoted in Gliddon, 2011).

\section{Consumer groups and concerns about privacy}

Consumer and privacy advocates welcome the emphasis on personal control and argue that it should be extended. Spokespeople for consumers resent them being positioned as incompetent, dependent and/or obstructive with regard to the PCEHR. In response to AMA comments that an 'unrepresentative few' have hijacked the technology, the CEO of the Consumers' Health Forum retorted: 'Consumers won't engage if there is an attitude that comes from the dark ages that doctor knows best ... Consumers have got to be in the driving seat or they won't adopt it' (quoted in Dunlevy, 2010). Similarly, the Consumers' e-Health Alliance (2011: 15) claims that 'Some consumers are better able to manage their medical information than their healthcare providers'. According to Consumers' Health Forum research, consumers want to be more actively engaged:

...consumers ... overwhelmingly argued that 'personal control' means more to them than simply having access to their record and setting access controls. Consumers have told [the Consumers' Health Forum] that they want to be able to actively participate in the management of their record, particularly through entering data and accessing information in a way that is convenient to them (Consumers' Health Forum, 2011: 4 emphasis in original).

The Office of the Information Commissioner also argued that consumers should have more control. It recommended extending the 'limited access' provision to the shared health summary, with consumers choosing which fields are included. It also recommended that consumers be able to set different levels of access for carers or family members allowed to see their records (Office of the Australian Information Commissioner, 2011). These calls for more nuanced controls would have added extra complexity to an already complex system, and the recommendations were not taken up. Instead, personal control was reduced, as the 'no access' option was removed, and doctors gained a right to view 'limited access' documents during emergencies (O'Brien, 2011).

\section{Update and discussion}

The story of the PCEHR in Australia is far from complete. Debates in the public regime of justification leading up to its introduction, outlined above, focused on disruptions to customary rights around the ownership of and access to electronic health data, as well as responsibilities for their completeness and quality. Calls by politicians and others to delay implementation so that more time could be spent exploring and addressing these disruptions were not heeded (Dearne, 2012c). Instead, registration opened as planned on 1 July 2012, even though software for loading data into the system would not be ready for several months (Connors, 2012). Registration was initially slow but escalated after a publicity campaign in 2013 (McDonald, 2013) and the deployment of 'sign-up squads' to hospitals and aged care facilities, a move which provoked some criticism (Dunlevy, 2013). 
By the end of July 2013, 2.7\% of a population of around 22 million had registered for a PCEHR, and 4,585 shared health summaries had been uploaded (National e-Health Transition Authority, 2013).

Possibilities for the PCEHR to reshape moral orders at the front line of healthcare delivery, that is, in situated encounters between patients and their providers, are only just being opened up as we write. How these possibilities play out will be the subject of future research. Existing ethnographic studies of the changes wrought by smaller electronic health record systems suggest that their use provokes subtle and unexpected changes in identities, relationships and work routines (Jensen, 2010; Vikkels $\emptyset, 2010)$. These changes are more complex than simply introducing 'better', more 'ordered' ways to organise work. Instead, they enable new practices to emerge that redistribute what counts as 'order' and 'disorder' (Berg \& Timmermans, 2000). As outlined above, there are already multiple orders in play among those who produce, use and regulate medical record keeping. The PCEHR cannot and will not resolve tensions among them by turning the perceived 'disorders' of a fragmented system into a new order of seamless integrated care. Instead, as a parallel system with ambiguous rights and responsibilities vis-à-vis the information it contains, it adds additional complexity. Only time will tell whether it will be another expensive failure or if it evolves into a technology that citizens and healthcare providers find useful. Prospects for the latter will be enhanced by opportunities for interested parties to work with and around the ambiguities opened up by the PCEHR. This requires more sophisticated processes of technology design and implementation than those pursued in Australia in recent years. Below we offer some suggestions for alternative ways to conceptualise and introduce complex healthcare technologies such as NEHRS that may help to accommodate and manage the multiple moral orders surrounding digital records.

\section{Discussion: digital disruption, intentions and the 'meta' moral ordering of NEHRS}

The difficulties that policymakers in many nations have experienced in their attempts to introduce NEHRS can be traced to a 'dangerous enthusiasm' for technology-driven fixes to complex social problems (Gauld \& Goldfinch, 2006). In their enthusiasm for NEHRS as a 'solution' to rising healthcare costs and increasing demand, policymakers focus on a version of digitalisation that assumes its worth is self-evident to both consumers and providers. The moral complexities surrounding the digital collection and sharing of health data - manifested for example in concerns over privacy and confidentiality - are treated as secondary problems that can be tidied up through the post hoc development of new procedures governing consent and access. As the experience in Australia illustrates, however, in practice these complexities are not so easily managed.

Instead of placing faith in technology, we suggest that policymakers need to recognise and understand the intentions of the multiple stakeholders involved in arenas such as healthcare before digitalisation is attempted. What we have in mind here is the facilitation of what might be termed a 'second order' or 'meta' mode of moral ordering whose purpose is to nurture collective and dynamic re-ordering among actors in a conscious attempt to identify, work through and rethink the rights and responsibilities that are appropriate for supporting the intentions of those who produce and use information to deliver care. This would involve much more than simple truncated 'consultations' around details of a pre-specified design, such as those that occurred in Australia in the lead up to the PCEHR. In the latter case, the 'consultations' inhibited exploration of the system's utility in the eyes of providers and consumers and instead fed concerns over privacy and governance.

Meta-ordering, on the other hand, would involve sustained interaction around 'boundary objects' such as prototypes and pilot trials, to allow the possibilities opened up by digitalisation to be explored alongside their implications for established patterns of rights and responsibilities. Such multi-stakeholder engagement in dialogues that attempt to build consensus would inevitably be time-consuming, difficult and messy, but may ultimately be more productive than rushed 
implementations that fail to engage potential users. It would not require a 'God's eye view' or a preordained endpoint towards which action is orchestrated, but rather a collective, facilitated journey that explores how things might be ordered differently. There are examples of such interactive reorderings around shared electronic health record systems in Australia and England, albeit in more localised contexts, that have generated productive results (see e.g. Garrety, Dalley, McLoughlin, Wilson, \& Yu, 2012; Jenkings \& Wilson, 2007; McLoughlin \& Wilson, 2013).

Scaling such examples up to a national or whole system level clearly presents major challenges, as heavy up front investments in the infrastructure required to support systems of innovation are needed. As a report for one UK innovation 'think tank' recently argued, getting returns on such investments requires considerable parallel resources for building alliances and developing a common purpose around a recognition of what is of value in order to change behaviour (Leadebeater, 2013).

As this article is being completed, the new Coalition Federal Government in Australia has announced a review of the future of the PCEHR (Foo, 2013b). Whether this review provides a catalyst for actors in the arena to seek a common understanding by working through their currently divergent intentions remains to be seen. Our fear is that left to its own devices the debate will once again be reduced to another round of polarising discourse. To get beyond this, we should neither simply put our faith in what are assumed to be the self-evident benefits and utility of the digitalisation of health data; nor should we just resist the technology because of fears concerning threats to privacy and confidentiality. To make some progress we need to develop the basis for a better kind of conversation about electronic health records than this.

\section{Acknowledgements}

This article is based on research conducted with the support of an Australian Research Council Discovery Grant, no. DP110100084.

\section{References}

Australian Medical Association, Submission to the Department of Health and Ageing on the draft concept of operations relating to the introduction of a personally controlled electronic health record system, 2011 http://ama.com.au/node/6777, Accessed 15.06.11.

Australian Medical Association, Guide to using the PCEHR, 2012 https://ama.com.au/ama-guideusing-pcehr, Accessed 28.09.12.

Ball M.J., Smith C.N. and Bakalar R.S., Personal health records: empowering consumers, Journal of Healthcare Information Management 21 (1), 2007, 77.

Berg M. and Harterink P., Embodying the patient: records and bodies in early 20th-century US medical practice, Body \& Society 10 (2-3), 2004, 13-41.

Berg M. and Timmermans S., Orders and their others: on the constitution of universalities in medical work, Configurations 8 (1), 2000, 31-61.

Berg M. and Winthereik B.R., Waiting for Godot, In: Berg M., (Ed), Health information management. Integrating information technology in health care work, Routledge Health Management Series 2004, 10-41.

Blume S., Anti-vaccination movements and their interpretations, Social Science \& Medicine 62 (3), 2006, 628-642.

Boltanski L. and Thévenot L., On justification: Economies of worth, 2006, Princeton University Press; Princeton.

Brennan S., The biggest computer programme in the world ever!, Journal of Information Technology 22 (3), 2007, 202-211. 
Bury M. and Taylor D., Towards a theory of care transition: from medical dominance to managed consumerism, Social Theory \& Health 6, 2008, 201-219.

Carvel J., Patients win right to keep records off NHS computer, The Guardian December 16, 2006 http://www.guardian.co.uk/society/2006/dec/16/health.epublic?INTCMP=SRCH, Accessed 28.02.11.

Christensen C.M., Grossman J.H. and Hwang J., The innovator's prescription: A disruptive solution for health care, 2009, McGraw-Hill; New York http://offwhitepapers.com/?p=21.

Clarke R., Just another piece of plastic for your wallet: the "Australia Card" scheme, Computers \& Society 18 (1), 1988, 7-21.

Clarke R., Balancing benefits against risks in the proposed health communications network, 1992 http://www.rogerclarke.com/DV/PaperHCN.html, Accessed 09.03.09._Clarke A., Situational analysis: Grounded theory after the postmodern turn, 2005, Sage.

Coiera E., Building a national health IT system from the middle out, Journal of the American Medical Informatics Association 16 (3), 2009, 271-273.

Coiera E., Kidd M. and Haikerwal M., A call for national e-health clinical safety governance, Medical Journal of Australia 196 (7), 2012, 430-431.

Connors E., Progress slow in electronic health push, Financial Review September 25, 2012 http://afr.com/p/technology/progress_slow_in_electronic_health_B6IOIgi5IYFejg5kyCPEMK, Accessed 26.09.12.

Consumers' e-Health Alliance, Review of the PCEHR draft concept of operations, 2011 http://www.yourhealth.gov.au/internet/yourhealth/blog.nsf/AFA3EEBA58421EC7CA2578DC00 03F72C/\$FILE/Consumers\%20e- Health\%20Alliance\%20submission.pdf, Accessed 01.10.12.

Consumers' Health Forum, Submission on the draft concept of operations relating to the introduction of a PCEHR, 2011 https://www.chf.org.au/pdfs/chf/Submission-to-the-PCEHRInquiry.pdf', Accessed 14.09.11.

Cross M., Health department and BMA may reach compromise on records system, British Medical Journal 336 (7658), 2008, 1398.

Dearne K., Feds' health data project stalls, The Australian June 7, 2005 http://search.ebscohost.com/login.aspx?direct=true\&db=n5h\&AN=200506076029038941\&site =ehost-live, Accessed 07.04.11.

Dearne K., Canberra stalls on e-health details, Australian IT February 3, 2009 http://global.factiva.com.ezproxy.uow.edu.au/aa/default.aspx?pp=Save\&hc=Publication, Accessed 07.04.11.

Dearne K., Sceptics warn of risks and inadequacies in shared e-health records system, Australian IT 2012a http://www.theaustralian.com.au/australian-it/government/sceptics-warn-of-risks-andinadequacies-in-shared-electronichealth-records/story-fn4htb9o-1226412887806, Accessed 01.10.12.

Dearne K., GPs want more money for e-health, The Australian 2012b http://www.theaustralian.com.au/australian-it/government/gps-want-more-money-for-ehealth/story-fn4htb9o-1226333927044, Accessed 27.04.12.

Dearne K., No shaking e-health record controversy, Australian IT 2012c http://www.theaustralian.com.au/australian-it/opinion/no-shaking-e-health-recordcontroversy/story-e6frgb0o-1226317677636, Accessed 13.04.12.

Deloitte, National E-Health Strategy, 2008 http://www.aph.gov.au/Senate/committee/clac_ctte/healthcare_identifier/submissions/sub22 e_DoHA.pdf, Accessed 22.03.10.

Department of Health and Ageing, Concept of operations: Relating to the introduction of a personally controlled electronic health record (PCEHR) system, 2011, Australian Government; 
Canberra

http://www.yourhealth.gov.au/internet/yourhealth/publishing.nsf/content/404ref.htm\#.Uco0 UqP2Qcs, Accessed 26.09.11.

Department of Health and Ageing, Welcome to ehealth.gov.au, 2012 http://www.ehealth.gov.au/internet/ehealth/publishing.nsf/content/home\#.T_pMssj4JLh, Accessed 06.07.12.

Deutsch E., Duftschmid G. and Dorda W., Critical areas of national electronic health record programs - is our focus correct?, International Journal of Medical Informatics 79 (3), 2010, 211-222.

Dunlevy S., AMA attacks e-health record plan, The Australian December 1, 2010 http://www.theaustralian.com.au/national-affairs/ama-attacks-e-health-record-plan/storyfn59niix-1225963522922, Accessed 07.02.11.

Dunlevy S., Outrage as eHealth record sign-up squads hit Australian hospital patients in bid to boost numbers, Herald Sun April 14, 2013 http://www.heraldsun.com.au/news/national/outrage-asehealth-record-sign-up-squads-hitaustralian-hospital-patients-in-bid-to-boost-numbers/storyfncynkc6-1226619874616, Accessed 22.07.13.

Foo F., Sector calls for transparency and end to mistakes in PCEHR, The Australian 2013a http://www.theaustralian.com.au/technology/sector-calls-for-transparency-and-end-tomistakes-in-pcehr/story-e6frgakx- 1226720434416, Accessed 19.09.13.

Foo F., "Avoid blame game in review": doctors' plea on e-health inquiry, The Australian 2013b http://www.theaustralian.com.au/technology/avoid-blame-game-in-review-doctors-plea-on-ehealth-inquiry/story-fn4htb9o-1226753031978, Accessed 08.11.13.

Fujitsu Consulting, The health connect implementation approach version 1.0, 2004 http://www.health.gov.au/internet/hconnect/publishing.nsf/Content/43598FE37A3E7270CA25 7128007B7EB7/\$File/ia_jan2005.pdf, Accessed 04.08.08.

Garfinkel H. and Bittner E., Good organizational reasons for "bad" clinic records, In: Garfinkel H., (Ed), Studies in ethnomethodology, 1967, Prentice-Hall; Englewood Cliffs, 186-207.

Garrety K., Dalley A., McLoughlin I., Wilson R. and Yu P., Managing collaboration across boundaries in health information technology projects, Studies in Health Technology and Informatics 178, 2012, 58-63.

Gauld R. and Goldfinch S., Dangerous enthusiasms: E-Government, computer failure and information systems development, 2006, University of Otago Press; New ZGliddon J., AMA pours cold water on PCEHR, again, September 12, $2011 \mathrm{http}: / /$ ehealthspace.org/news/ama-pours-cold-waterpcehr-again, Accessed 27.09.11.

Greenhalgh T., Russell J., Ashcroft R. and Parsons W., Why national ehealth programs need dead philosophers, Milbank Quarterly 89 (4), 2011, 533-563.

Hackl W.O., Hoerbst A. and Ammenwerth E., Why the hell do we need electronic health records?, Methods of Information in Medicine 50 (1), 2011, 53-61.

Harré R., Moghaddam F.M., Cairnie T.P., Rothbart D. and Sabat S.R., Recent advances in positioning theory, Theory and Psychology 19 (1), 2009, 5-31.

Harris R., Wathen N. and Wyatt S., (Eds.), Configuring health consumers: Health work and the imperative of personal responsibility, 2010, Palgrave Macmillan; London.

Hughes E.C., The sociological eye: Selected papers, 1971, Transaction Publishers.

Hunt J., Rt.Hon, 'Paperless NHS' News Story Gov.UK, February 1, 2013 https://www.gov.uk/government/news/paperless-nhs-jeremy-hunt-leads-discussion, Accessed 20.09.13.

Jenkings K.N. and Wilson R.G., The challenge of electronic health records (EHRs) design and implementation, Informatics in Primary Care 15 (2), 2007, 93-101. 
Jensen C.B., Ontologies for developing things: Making health care futures through technology, 2010, Sense Publishers.

Laine C. and Davidoff F., Patient-centered medicine, JAMA 275 (2), 1996, 152-156.

Langenhove L.V. and Harré R., Cultural stereotypes and positioning theory, Journal for the Theory of Social Behaviour 24 (4), 1994, 359-372.

Leadebeater C., The systems innovator: Why successful innovation goes beyond products, 2013, NESTA; London.

McDonald K., \$10m ad campaign for Medicare and PCEHR begins, Pulse+IT June 11, 2013 http://www.pulseitmagazine.com.au/index.php?option=com_content\&view=article\&id=1461:1 Om-ad-campaign-for-medicare-and-pcehrbegins\&catid=16:australian health\&Itemid=327\&utm_source=Pulse\%2BIT++eNewsletters\&utm_campaign=a596d6ada3Pulse_IT_eNews_14_06_2013\&utm_medium=email\&utm_term=0_b39f06f53f-a596d6ada3413010505\&mc_cid=a596d6ada3\&mc_eid=d84b35c456, Accessed 15.07.13.

McLoughlin I.P. and Wilson R., Digital government at work: A social informatics perspective, 2013, Oxford University Press; Oxford.

Morrison Z., Robertson A., Cresswell K., Crowe S. and Sheikh A., Understanding contrasting approaches to nationwide implementations of electronic health record systems: England, the USA and Australia, Journal of Healthcare

Engineering 2 (1), 2011, 25-42.

National e-Health Transition Authority, Submission to senate enquiry: Personally controlled electronic health records (PCEHR) bill 2011 and one related bill, 2012 https://senate.aph.gov.au/submissions/comittees/viewdocument.aspx?id=8d7ac494-dfec4531-921b-d9bbb6ff6062, Accessed 11.01.12.

National e-Health Transition Authority, NEHTA Scorecard August 2013, 2013 http://www.nehta.gov.au/component/docman/doc_download/1777-nehta-scorecard-august2013? Itemid=, Accessed 01.09.13.

National Health and Hospitals Reform Commission, A healthier future for all Australians, Final report2009a, Australian Government; Canberra http://www.health.gov.au/internet/nhhrc/publishing.nsf/Content/nhhrc-report, Accessed 15.03.11.

National Health and Hospitals Reform Commission, Person-controlled electronic health records, 2009b, Australian Government; Canberra http://www.health.gov.au/internet/nhhrc/publishing.nsf/Content/BA7D3EF4EC7A1F2BCA2575 5B001817EC/\$File/Person-controlled\%20Electronic\%20Health\%2ORecords.pdf, Accessed 09.07.10.

O'Brien M., Privacy override could "undermine confidence" in e-health system, Medical Observer September 20, 2011 http://www.medicalobserver.com.au/news/privacy-override-couldundermine-confidence-in-ehealthsystem, Accessed 27.09.11.

Office of the Australian Information Commissioner, Submission to: Draft Concept of Operations: Relating to the introduction of a personally controlled electronic health record (PCEHR) system, 2011 http://www.yourhealth.gov.au/internet/yourhealth/blog.nsf/1C159A08257488D5CA2578DF00 21BF4D/\$FILE/Office\%20of\%20the\%20Australian\%20Information\%20Commissioner\%20\%280AI C\%29\%20submission.pdf, Accessed 28.09.11.

Purves I., Concepts in health informatics, In: Simpson L. and Robinson P., (Eds.), e-clinical governance: A guide for primary care, 2002, Radcliffe Medical Press. 
Ramli D., GPs to pay, says AMA, Financial Review May 10, 2012 http://afr.com/p/national/budget/gps_to_pay_says_ama_2e3aY29RciaQFMDKxOEnSL, Accessed 10.05.12.

Rauber C., Kaiser Permanente completes rollout of electronic medical records, Washington Business Journal May 6, 2008 http://www.bizjournals.com/washington/stories/2008/05/05/daily29.html, Accessed 25.06.09.

Reiser S.J., The clinical record in medicine part 1: Learning from cases, Annals of Internal Medicine 114 (10), 1991a, 902-907.

Reiser S.J., The clinical record in medicine Part 2: Reforming content and purpose, Annals of Internal Medicine 114 (11), 1991b, 980-985.

Ross S.E. and Lin C.T., The effects of promoting patient access to medical records: a review, Journal of the American Medical Informatics Association 10 (2), 2003, 129-138.

Royal Australian College of General Practitioners, Handbook for the management of health information in private medical practice, 2002 http://www.racgp.org.au/privacy/handbook, Accessed 14.06.12.

Royal Australian College of General Practitioners, Position statement: Personally Controlled Electronic Health Record (PCEHR), 2011a http://www.racgp.org.au/AM/Template.cfm? Section=ehealthPCEHR\&Template=/CM/ContentDisplay.cfm\&ContentID=43401, Accessed 27.09.11.

Royal Australian College of General Practitioners, Submission to the Department of Health and Ageing on the personally controlled electronic health record system: Legislation issues paper, 2011b

http://www.yourhealth.gov.au/internet/yourhealth/blog.nsf/0B3BC405CA522FACC9A25791A0 0090F6E/\$FILE/62.RACGP,\%20Judy\%20Evans\%20-\%20Att1.pdf, Accessed 03.10.12.

Royal Australian College of General Practitioners, PCEHR and the use of item numbers in general practice, 2012 http://www.racgp.org.au/yourracgp/news/news/pcehr-and-the-use-of-itemnumbers-in-general-practice/, Accessed 13.06.13.

Siegler E.L., The evolving medical record, Annals of Internal Medicine 153 (10), 2010, 671-677.

Simonds W. and Ellertson C., Emergency contraception and morality: reflections of health care workers and clients, Social Science \& Medicine 58 (7), 2004, 1285-1297.

Sinding C., Hudak P., Wiernikowski J., Aronson J., Miller P. and Gould J., "I like to be an informed person but..." negotiating responsibility for treatment decisions in cancer care, Social Science \& Medicine 71 (6), 2010, 1094-1101.

Smits J., The future of the national virtual EPR in the Netherlands, Journal of Chain-Computerisation 4, 2013, 3-15.

Star S.L. and Ruhleder K., Steps toward an ecology of infrastructure: design and access for large information spaces, Information Systems Research 7 (1), 1996, 111-134.

Strauss A., Interorganizational negotiation, Urban Life 11 (3), 1982, 350-367.

Strauss A., Fagerhaugh S., Suczek B. and Wiener C., Social organization of medical work, 1985, University of Chicago Press; Chicago.

Strauss A., Schatzman L., Ehrlich D., Bucher R. and Sabshin M., The hospital and its negotiated order, In: Freidson E., (Ed), The hospital in modern society, 1963, Free Press; New York.

Stroetmann K.A., Artmann J., Stroetmann V.N., Whitehousee D., Protti D., Dumortier J., et al., European countries on their journey towards national eHealth infrastructures, 2011 http://www.ehealthstrategies.eu/report/eHealth_Strategies_Final_Report_Web.pdf, Accessed 22.11.12. 
Thévenot L., Pragmatic regimes governing the engagement with the world, In: Cetina K.K., Schatzki T. and Von Savigny E., (Eds.), The practice turn in contemporary theory, 2001, Routledge, 56-73.

Townsend R., Doctors and patients uneasy about new e-health records system, The Conversation July 5, 2012 http://theconversation.edu.au/doctors-and-patients-uneasy-about-new-e-healthrecords-system-7706, Accessed 06.07.12.

Vikkels $\varnothing$ S., Mobilizing information infrastructure, shaping patient-centred care, International Journal of Public Sector Management 23 (4), 2010, 340-352.

Westbrook J.I. and Braithwaite J., Will information and communication technology disrupt the health system and deliver on its promise?, Medical Journal of Australia 193 (7), 2010, 399-400.

Willis E., Medical dominance: The division of labour in Australian health care, 1983, George Allen \& Unwin.

Willis E., Reynolds L.E. and Keleher H., Understanding the Australian health care system, 2008, Elsevier Australia. 